\title{
A arquitetura e Schopenhauer. \\ O problema da fruição e o lugar da arquitetura na teoria estética schopenhaueriana
}

\author{
Architecture and Schopenhauer. The problem of the fruition and the \\ place for architecture in Schopenhauer's \\ aesthetic theory
}

\author{
Gustavo Bezerra do Nascimento Costa \\ Doutor em Filosofia pela UERJ \\ Professor colaborador da Universidade Estadual do Ceará (UECE) \\ em estágio pós-doutoral (PNPD-UECE/CAPES). \\ E-mail: arqgustavocosta@hotmail.com
}

\begin{abstract}
Resumo: No presente artigo, esboço uma problematização acerca do pensamento estético de Schopenhauer, particularmente no que diz respeito à sua análise sobre a arquitetura e a fruição do objeto arquitetônico. Pretendo abrir duas vertentes de análise, relativas a duas inquietações minhas: primeiramente, a compreensão da arquitetura em termos da submissão a relações causais e fins utilitários, deixando entrever, com isso, certa filiação de Schopenhauer aos cânones da arquitetura neoclassicista. Depois, o modo mesmo de fruição do objeto arquitetônico, limitada à contemplação visual, tendo como corolário a distinção, a meu ver, precária, entre a arquitetura e o artefato. A guisa de conclusão, procuro amalgamar tais inquietações levantando a necessidade de uma distinção entre hierarquia e transversalidade no que tange a uma compreensão da leitura estética presente no Livro III de O mundo como vontade e como representação.
\end{abstract}

Palavras-chave: Arquitetura; Artefato; Fruição estética; Neoclassicismo.
Abstract: In this article, I outline a questioning on Schopenhauer's aesthetic thought, particularly regarding to his analysis on architecture and the fruition of the architectural object. I intend to open two strands of analysis relating to two concerns: first, the understanding of the architecture in terms of a submission to causal relationships and utilitarian purposes, leaving foresee certain affiliation of Schopenhauer to the canons of neoclassical architecture. Second, the mode of fruition of the architectural object, limited to a visual contemplation, having as corollary - in my point of view - the precarious distinction between architecture and the artifact. As a matter of conclusion, I try to amalgamate these concerns by raising the necessity of a distinction between hierarchy and transversality concerning to a comprehension of the aesthetic reading present in Book III of The World as Will and Representation.

Keywords: Architecture; Artifact; Aesthetic fruition; Neoclassicism. 
Como se sabe, no Livro III de O mundo como vontade e como representação, Schopenhauer toma como próprio do conhecimento artístico a consideração unicamente do essencial do mundo ${ }^{1}$, cujo correlato subjetivo seria o puro sujeito de conhecimento, constituindo com ele a objetidade mais adequada da Vontade, ainda não mediada pelo princípio de razão ${ }^{2}$. Tal modo de conhecimento, a fruição, implicaria um deslocamento do objeto em relação ao curso do mundo ${ }^{3}$ - isto é, sua contemplação independentemente do espaço, tempo e causalidade ${ }^{4}$ - fazendo emergir, do objeto, precisamente o seu arquétipo: a ideia que lhe corresponde. Cada manifestação artística, nesse sentido, corresponderia, hierarquicamente, a um grau de objetidade da Vontade, segundo um maior ou menor distanciamento do conteúdo que ela apresenta em relação ao princípio de razão. A arquitetura, nas palavras de Schopenhauer, expressaria o essencial das forças fundamentais da natureza, ou seja, traria à intuição precisamente "os graus mais baixos" dessa objetidade ${ }^{5}$, aqueles em que ainda é grave a discordância da Vontade consigo mesma - mais próximos, nesse sentido, da matéria inerte. Isto teria, ao que parece, duas implicações.

Primeiramente, o fato de que "a significação objetiva daquilo que a arquitetura nos manifesta" seria "relativamente pequena" ${ }^{6}$. Ou seja, a fruição estética que proporcionaria a visão de um belo edifício não repousaria "tanto na apreensão da Ideia, mas antes, no correlato subjetivo dela posto com essa apreensão" ${ }^{\text {. Nesse }}$ sentido, dependeria bem mais do espectador - "que se desprende do modo de conhecimento próprio do indivíduo" - do que propriamente do objeto. Daí a necessidade, para Schopenhauer, de sua fruição vir acompanhada do "conhecimento intuitivo e imediato de sua matéria, relacionado ao peso, à rigidez e à coesão"8. Em segundo lugar, enquanto expressão das forças fundamentais da natureza, apenas um tema estético emergiria da arquitetura: a ainda grave (ou seja, ainda não aguda) discórdia da Vontade consigo mesma. O belo, o essencial da

\footnotetext{
1 SCHOPENHAUER, A. WWV-I/MVR-I § 36, p. 251.

2 Idem § 41, p. 283.

3 Idem § 36, p. 253.

4 Idem § 36, p. 254.

5 Idem § 43, p. 288-290.

6 Idem § 43, p. 291.

7 Ibidem.

8 Idem § 43, p. 289.
}

A arquitetura e Schopenhauer. O problema da fruição e o lugar da arquitetura na teoria estética schopenhaueriana 
arquitetura, diz Schopenhauer, manifestar-se-ia na luta entre gravidade e rigidez ${ }^{9}$ e, simultaneamente, naquilo a que se contrapõem: a $l u z^{10}$. Nesse sentido, um objeto arquitetônico seria belo quando desviasse da maneira mais adequada, clara e distinta possível da gravidade, deixando entrever, nesse desvio, a luz como seu contraponto ${ }^{11}$.

O corolário destas duas implicações seria que, para Schopenhauer, o fim estético da arquitetura não poderia ir além da...

... finalidade visível de suas partes, não para fins humanos exteriores e arbitrários (nesse sentido, a obra pertence à arquitetura utilitária) mas imediatamente para a estabilidade do todo, em vista da qual a posição, a grandeza e a forma têm de ter uma relação tão necessária que, caso fosse possível remover uma única parte, o todo desmoronaria [grifos nossos] ${ }^{12}$.

A forma de cada parte de um edifício, nesse sentido, não deve ser determinada arbitrariamente, "mas por seu fim e em relação com o todo" (ibidem). Por exemplo, uma coluna bela seria aquela que, tanto mais quanto mais simplesmente, for determinada por seu fim, qual seja, o sustento.

Passo, então, às inquietações.

\section{A arquitetura e a beleza parcimoniosa}

A primeira delas diz respeito ao mínimo de beleza concedido ao objeto arquitetônico: belo é aquilo que escapa ao útil, porém, apenas raramente isto lhe ocorre. Tal parcimônia deriva em parte de que, diferentemente das outras artes "visuais" - deixemos de lado o abstracionismo, impensável à época de Schopenhauer - a arquitetura não nos fornece uma cópia, mas a coisa mesma. Não haveria, nesse sentido, como furtar-se aos imperativos da utilidade. Quase que inevitavelmente, a submissão primeira seria aos fins utilitários ${ }^{13}$ e só uma pequena margem lhe seria concedida, de escape à causalidade. Como Schopenhauer afirma nos Complementos a $O$ mundo...: se por um lado, a mãe "das artes belas é a

9 Idem § 43, p. 288. 
abundância", a "das artes úteis é a necessidade"14. Caberia então ao arquiteto: "Alcançar e impor [estes] fins puramente estéticos, apesar de sua subordinação a fins estranhos", leia-se: fins utilitários ${ }^{15}$.

Ora, a despeito dessa incumbência, é a estes mesmos fins que Schopenhauer parece render-se em sua avaliação do belo no objeto arquitetônico. Nos Complementos, considera que a arquitetura seria regida por um tema permanente: carga e apoio, e por uma lei fundamental: "Nenhuma carga sem apoio suficiente e nenhum apoio sem carga adequada', de modo que a proporção entre ambas seja precisamente a apropriada"16. Tal lei, ao que parece, acabaria por submeter o princípio estético da arquitetura a uma determinada dimensão utilitária ou princípio de economia. Em certo sentido, a passagem de Schopenhauer: "As formas da arquitetura se determinam, antes de tudo, pela imediata finalidade construtiva de cada parte", antecipa em pouco mais de um século a famosa (mas mal compreendida) frase do arquiteto protomodernista Louis Sullivan: "a forma segue a função"17 - máxima que viria a constituir um dos cânones da arquitetura racionalista do século $X X$. Seguindo essa compreensão, parece que chegamos a um paradoxo: para ser bela, a arquitetura deveria romper de algum modo com a subordinação ao utilitário; porém, sua beleza viria com o cumprimento a uma lei que é, em última instância, utilitária. O problema, então, diria respeito à insistência em restringir ou reduzir a beleza a uma adequação material, regida por uma lei, que não é menos que a lei fundamental da economia da construção: nenhum suporte sem carga, nenhuma carga sem suporte - portanto: nada em falta ou em demasia. Tal concepção iria de encontro precisamente à sua noção de belo como aquilo que escapa ou que suplanta a causalidade. E nesse sentido, como grau mais baixo de objetidade da Vontade, não restaria à arquitetura, senão, a possibilidade de ser bela sem sê-la.

Poder-se-ia contra-argumentar que, ainda que em direta oposição à teoria kantiana - "que põe a essência do belo em uma aparente finalidade sem fim"18 Schopenhauer deixa claro que, com a atenção à "finalidade visível" das partes de

14 SCHOPENHAUER, A. WWV-II/MVR-II, cap. 34, p. 458. 15 SCHOPENHAUER, A. WWV-I/MVR-I § 43, p. 291. 16 SCHOPENHAUER, A. WWV-II/MVR-II, cap. 35, p. 459. 17 A frase na íntegra seria: "se a forma segue a função, então o trabalho deve ser orgânico". 18 SCHOPENHAUER, A. WWV-II/MVR-II, cap. 35, p. 464. 
um edifício, não se refere a seus fins "exteriores" ou "humanamente" utilitários. De fato, a arquitetura, por representar os graus mais baixos de objetidade da Vontade, dependeria, para sua fruição, muito mais do espectador - do puro sujeito do conhecimento - que do objeto por ele contemplado. Nesse sentido, não se trata, com a ideia de finalidade, da adequação dos espaços aos propósitos a que se destinam, mas sim, como dissemos acima, da adequação visível das partes relativa à estabilidade do todo ${ }^{19}$ - ou antes, da finalidade relativa à impressão de estabilidade do todo. Caberia ao objeto arquitetônico, apenas, não criar empecilhos àquela fruição, isto é, à intuição mais perfeita e imediata. Por isso é que seus elementos constitutivos devem ser claros e distintos, suas medidas, proporcionais e adequadas, e sua composição, simétrica. Cada forma, enfim, ao seu propósito.

Ora, ainda que cedêssemos a essa linha de argumentação, partindo de uma crítica, digamos, exógena, toda a preocupação de Schopenhauer concernente à fruição da arquitetura nos termos de uma impressão de estabilidade e adequação visível das partes em relação ao todo poderia ser situada no âmbito daquilo que veio depois a ser compreendido como psicologia da Gestalt ou psicologia da forma particularmente, no que diz respeito a alguns dos princípios que regem nossa percepção visual, dentre os quais: a tendência à estruturação, a segregação figurafundo, a constância perceptiva e, principalmente, a pregnância [Prägnanz], isto é, a capacidade da nossa visão de, mais facilmente, adaptar-se a um determinado campo visual.

Pregnância visual, como bem aponta Rudolf Arnheim, não significa uma disposição passiva visando à estrutura mais simples, mas antes, uma tendência ativa a "tornar a estrutura perceptiva mais nítida possível" 20 . Um campo com baixa pregnância, nesse sentido, seria aquele ao qual nossa visão teria mais dificuldade em adaptar-se, aumentando com isso nosso estímulo visual, nossa tensão perceptiva, a ponto de tornar a apreensão do objeto cansativa. Mas por outro lado, formas demasiadamente simples e facilmente apreendidas, embora transmitindo com clareza uma mensagem visual, por fim, já não despertariam nosso interesse. Seguindo essa linha de pensamento, poderíamos dizer que percebemos mais facilmente as boas formas, ou seja, as formas simples, regulares, simétricas e 
equilibradas, "claras e distintas". Mas se elas não suscitarem suficiente estímulo, tenderiam a passar despercebidas. Para ser atraente, portanto, o objeto artístico haveria de buscar um ponto ótimo entre pregnância e tensão visual.

Ora, é precisamente o elemento de tensão que Schopenhauer suprime em sua compreensão do belo, em favor do linimento ante a incessante Roda de íxion, da satisfação que reduz a oscilação do pêndulo. A contemplação estética, nesse sentido, estaria em perfeito acordo com seu pensamento único: o belo não deve despertar o interesse, ou seja, excitar - e sim, acalmar. Mas do mesmo modo, estaria também em perfeito acordo com a corrente estética neoclassicista então vigente (exemplificada abaixo) - de quem Schopenhauer, ao que parece, mostra-se devedor.

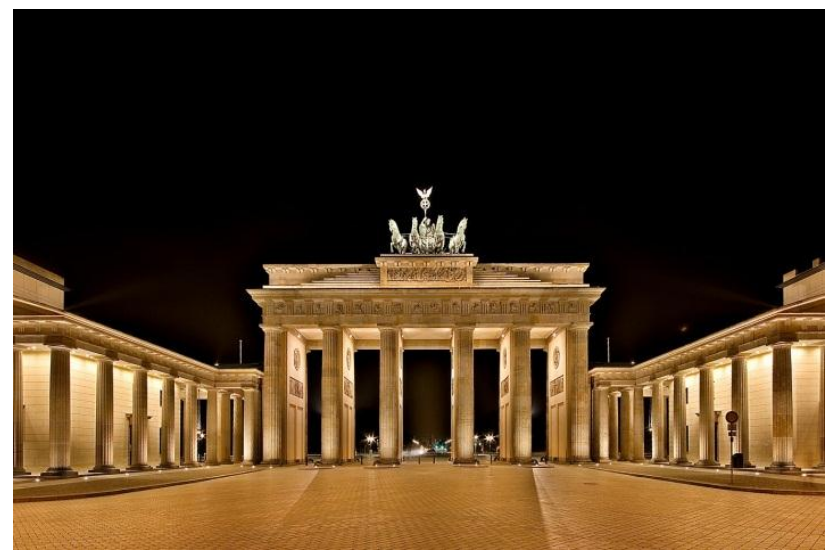

Imagem 1: Brandenburg Tor (1793). Arq. Carl Gotthard Langhans.

(Thomas Wolf, www.foto-tw.de - Eigenes Werk. Disponível em: https://de.wikipedia.org/wiki/Brandenburger Tor)

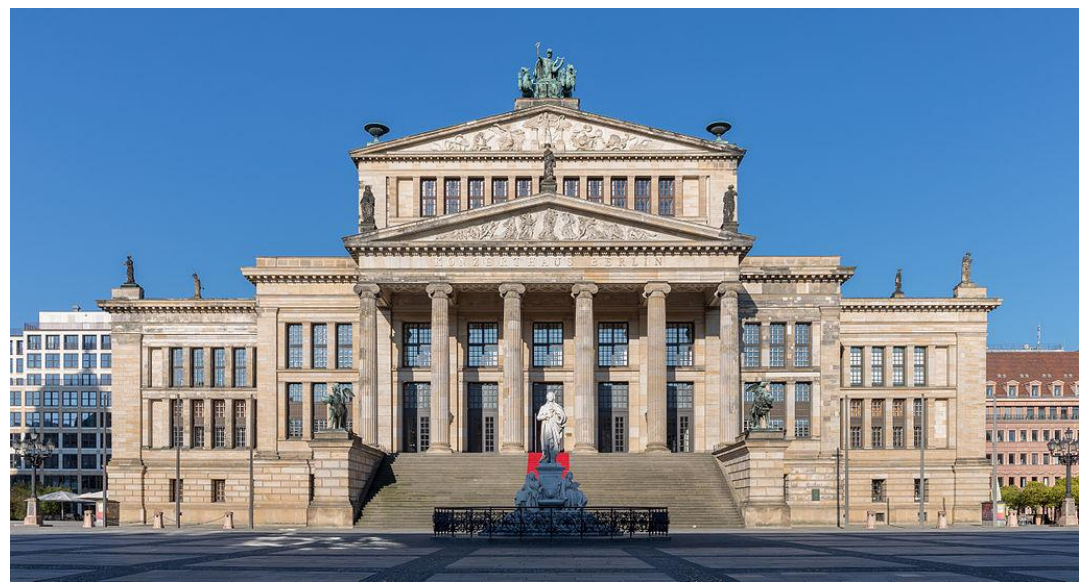

Imagem 2: Berliner (Königliches) Schauspielhaus (1821). Arq. Karl Friedrich Schinkel.

(Ansgar Koreng / CC BY 3.0 (DE). Disponível em: https://de.wikipedia.org/wiki/Schauspielhaus Berlin) 
Novamente com Arnheim, poder-se-ia tomar como próprio do classicismo, em suas diversas "aparições", a tendência à "simplicidade, simetria, normalidade e redução de tensão" ${ }^{21}$. Por sua vez, pensada em função do desvencilhamento "claro e distinto" da matéria, de modo a tornar possível a fruição da já parca, modesta beleza arquitetônica, a metafísica schopenhaueriana (re)anuncia: a valorização do dimensionamento racional dos apoios, a preponderância estética do sistema viga/coluna (pórtico) em relação ao sistema de abóbadas, bem como dos telhados planos (ou quase planos) sobre os inclinados. Schopenhauer chega mesmo a ter como uma redução de alegria (e portanto, algo negativo) a revelação, por exemplo, de que o material com o qual um edifício, pretensamente rígido e coeso, fora construído era a pedra-pomes ${ }^{22}$. Do mesmo modo, a contemplação de um edifício em madeira jamais suscitaria a beleza que, pela impressão de rigidez, um edifício em pedra nos transmite.

Pois bem, válida segundo a sua metafísica do belo - pensada mesmo em função do encaixe em sua classificação hierárquica - esta compreensão teria como contrapartida a exclusão, ou pelo menos a recusa - como "inapropriada" - de um vasto campo estético na arquitetura, que tem precisamente na tensão, na dramaticidade, o seu leitmotiv. Por outro lado, oposto ao classicismo, o expressionismo, em suas diversas apresentações, enfatizaria: "o irregular, o assimétrico, o incomum e o complexo, e se esforça para aumentar a tensão" visual ${ }^{23}$. Ora, o que se perde então com o encaixe da arquitetura na estética schopenhaueriana, é precisamente esse elemento de expressividade, de dramaticidade, que ele de pronto toma como diametralmente oposto à arquitetura ${ }^{24}$. O campo estético que vem à mente é precisamente aquele que foi rejeitado com a valorização dos preceitos clássicos vitruvianos (então redescobertos) - aí se incluindo a entediante simetria. Mais do que a expressividade gótica - amiúde referida por Schopenhauer nos Complementos - "inapropriado" é o elemento de tensão, dramaticidade e subversão - incluindo a subversão de sentido - que desde o Barroco até as correntes organicistas da arquitetura moderna ${ }^{25}$ compõe o

21 ARNHEIM, Rudolf. Arte e percepção visual, p. 59 22 SCHOPENHAUER, A. WWV-I/MVR-I § 43, p. 289 23 ARNHEIM, Rudolf. Arte e percepção visual, p. 59 24 SCHOPENHAUER, A. WWV-I/MVR-I § 43, p. 291

25 Não por acaso, já em meados do século XX, Oscar Niemeyer foi criticado por alguns arquitetos europeus (como Max Bill) que viam em sua arquitetura um abuso do que se poderia chamar de princípio de economia e o prenúncio (como afirmou Le Corbusier) de um retorno ao Barroco. 
repertório artístico arquitetônico, conforme exemplificado abaixo:
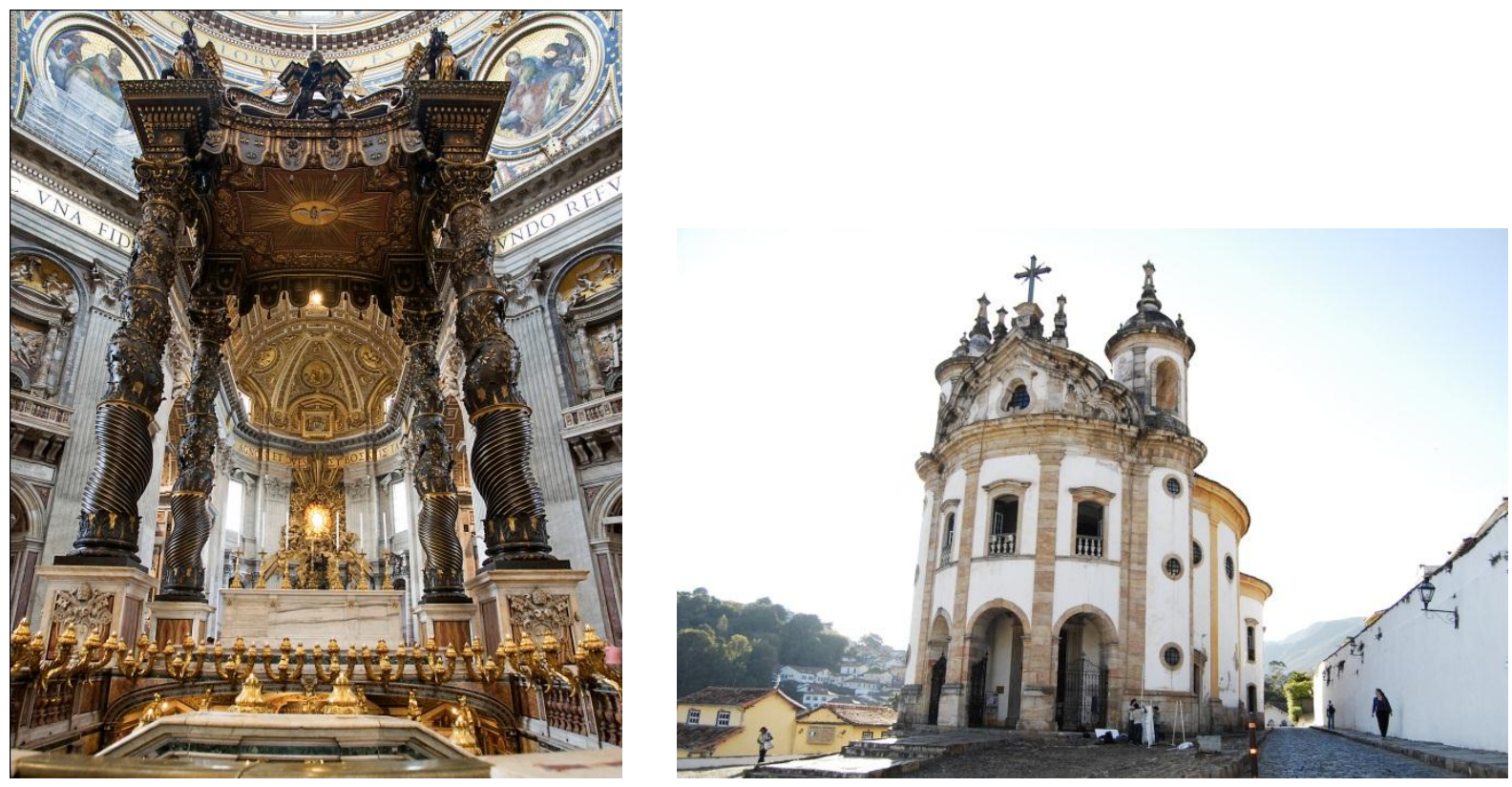

Imagem 3: Baldaquino da Basílica de São Pedro (1633). Arq. Gian Lorenzo Bernini.

(Jorge Royan - File:Basilica di San Pietro, Rome - 2677.jpg. Disponível em: https://pt.wikipedia.org/wiki/Bas\%C3\%ADlica de S\%C3\%A3o Pedro)

Imagem 4: Igreja de Nossa Senhora do Rosário dos Pretos (1761-1823). Autor desconhecido. (Ricardo André Frantz. CC BY 3.0. Disponível em:

https://pt.wikipedia.org/wiki/lgreja de Nossa Senhora do Rosário dos Homens Pretos (Ouro Preto)

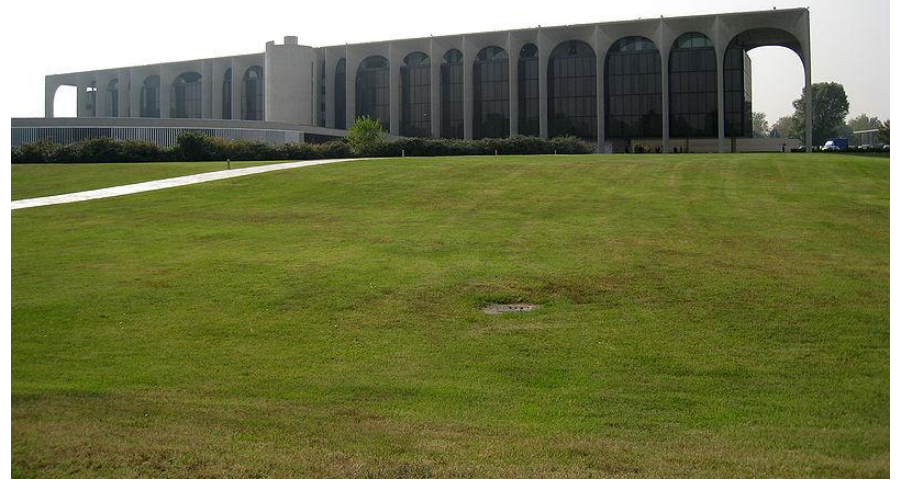

Imagem 5: Sede da Editora Mondadori, Milão (1968). Arq. Oscar Niemeyer.

(Nitot. Disponível em: https://pt.wikipedia.org/wiki/Arnoldo Mondadori Editore) 


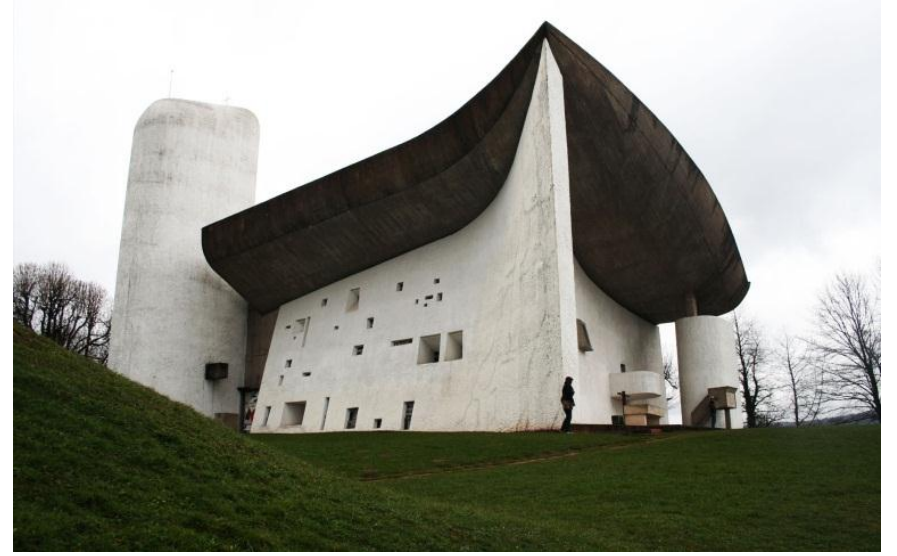

Imagem 6: Capela Notre-Dame du Haut (1955). Arq. Le Corbusier.

(Luke Stearns. Disponível em: http://www.archdaily.com.br/br/01-16931/classicos-da-arquitetura-capelade-ronchamp-le-corbusier)

É curioso e bastante indicativo a esse respeito que, embora a fruição em arquitetura dependa bem mais do puro sujeito de conhecimento, Schopenhauer centre suas análises somente nas disposições do objeto arquitetônico contemplado - cujas características apenas não devem obstruir a fruição. Caso voltasse sua atenção ao polo subjetivo da fruição estética (redundância), provavelmente teria antevisto que, com a recusa da expressividade, deixa-se também de lado aquela que seria a própria manifestação do sublime dinâmico na arquitetura, enquanto aumento da tensão e angústia provocadas pela "visão de uma potência superior e ameaçadora", com o correlato aumento da capacidade de o indivíduo suportá-las ${ }^{26}$ isto, ainda no âmbito da contemplação destituída de vontade.

A meu ver, qualquer tentativa de se repensar a teoria estética schopenhaueriana na contemporaneidade haveria de considerar, não apenas a revolução estética protagonizada pelo abstracionismo nas artes visuais, mas também o desenvolvimento das técnicas e materiais que configuram as "artes úteis", como a arquitetura. Tais potencialidades, a meu ver, suplantam a estreiteza das limitações técnicas e estruturais da época de Schopenhauer - em última instância, calcadas na pedra - e dão azo a um repensar dos limites de sua teoria, pelo menos, no que diz respeito à arquitetura: a tecnologia do concreto armado e as que the 
seguem, por exemplo, permitem uma maleabilidade estrutural e uma vitória sobre gravidade nunca antes imaginada, como ilustrado pela imagem abaixo.

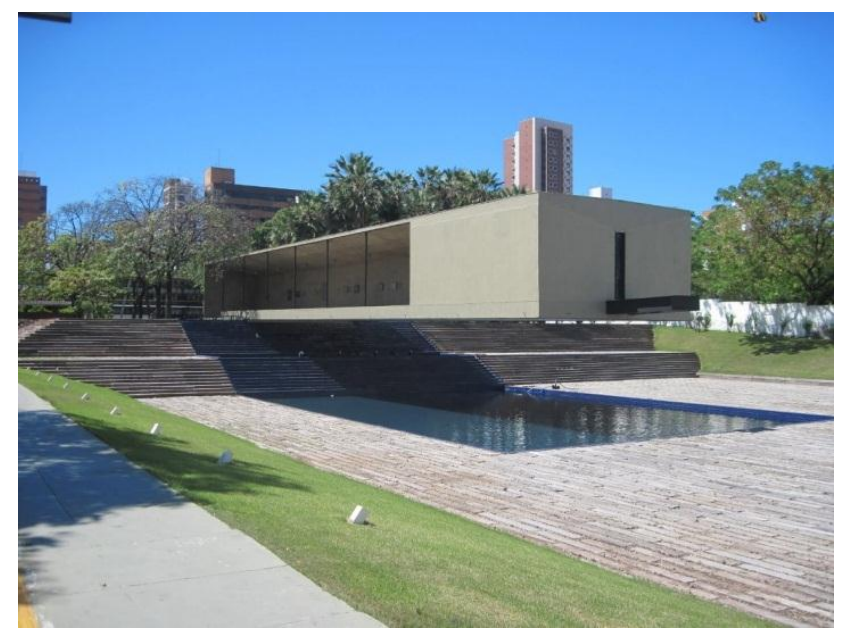

Imagem 7: Palácio da Abolição, Fortaleza (1968). Arq. Sérgio Bernardes (Fonte: Gabinete do Governador. Disponível em: http://www.institutopinheiro.org.br/)

Da mesma forma, a simetria, que nos dias de hoje já não suscita mais que o tédio, dá lugar aos elementos de tensão, subversão e dramaticidade que se configuram sob outro parâmetro de organização do campo visual chamado de equilíbrio dinâmico.

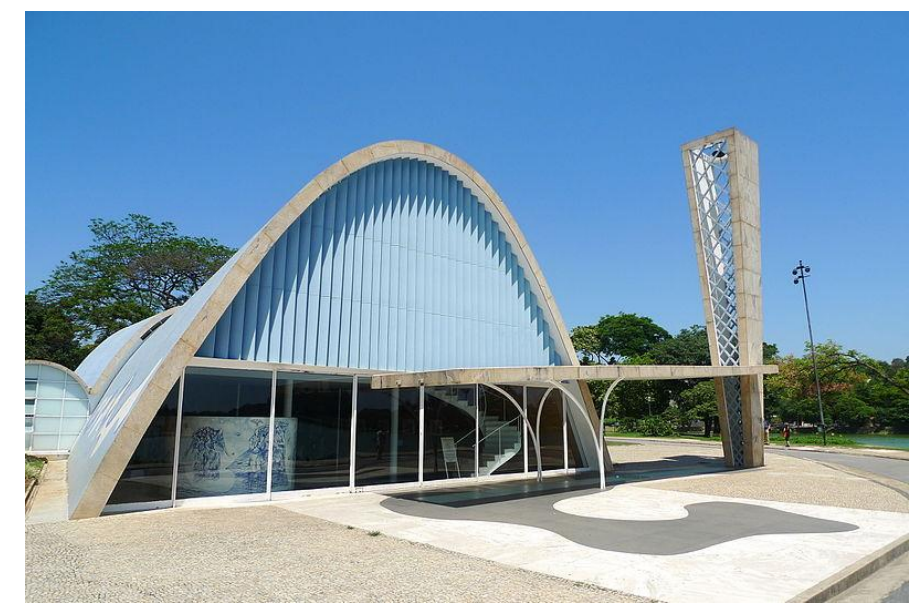

Imagem 8: Igreja São Francisco de Assis, Pampulha (1943). Arq. Oscar Niemeyer. (Matthias Ripp - Flickr. Disponível em: https://pt.wikipedia.org/wiki/lgreja_de_São_Francisco_de_Assis_(Belo_Horizonte))

Certamente é uma questão ético-pedagógica, essa que me inquieta: a nossa 
capacidade de nos tornarmos mais (ou menos) tolerantes - na arquitetura como na música, por exemplo - à tensão, ao dramático e ao feio. Nesse sentido, é algo não apenas extrínseco como extemporâneo ao pensamento de Schopenhauer. Isto, porém remete a um pano de fundo fisiológico que não pode ser, sem mais, descartado. "O excitante [...] é em toda parte para ser evitado na arte", diz Schopenhauer $^{27}$ - e Nietzsche viu bem onde essa recusa desembocaria: numa estética covarde, cuja ânsia por estabilidade e fixidez recua diante do tenso e do desconhecido.

\section{A fruição do espaço arquitetônico}

A segunda inquietação que me move a esta escrita diz respeito à compreensão schopenhaueriana de que a fruição estética na arquitetura dependeria da contemplação, isto é, da visão de um belo edifício. Isto porque, se há algo, de certo modo, consensual entre os teóricos da arquitetura, é que o elemento visual, embora determinante, não é suficiente para abarcar a relação multidimensional que o sujeito estabelece com o objeto arquitetônico. Para autores como Bruno Zevi (Saber ver a arquitetura) - que inclusive faz referência a Schopenhauer - mesmo templos como os dos gregos não poderiam ser considerados propriamente como arquitetura, na medida em que se destinariam à contemplação meramente visual (e à morada de seus deuses). O essencial da arquitetura, diz Zevi, não deve ser buscado aí, na mera contemplação, mas em seu protagonista: o espaço. É ele que distingue o objeto arquitetônico da escultura, da cenografia, ou mesmo, pra nos aproximarmos de Schopenhauer, do artefato [Artefakt]. Mas em sua compreensão, como afirma Zevi, devem ser evitados dois equívocos: a) o de tomar pelo conceito de "espaço" unicamente o interior do edifício, como se não houvesse um espaço urbanístico - e a Acrópole o é; e b) o de tomar o protagonista "espaço" como critério único que esgotaria a experiência arquitônica ${ }^{28}$. Espaço, pra abreviar as suas palavras, é tudo aqui que nos acolhe, qualquer que seja a escala e o fechamento.

A meu ver, esta complicação relativa ao objeto arquitetônico bem poderia ter sido antevista por Schopenhauer, caso tivesse feito jus à sua apologia da simetria e

27 SCHOPENHAUER, A. WWV-I/MVR-I § 40, p. 281

28 ZEVI, Bruno. Saber ver a arquitetura, p. 25.

A arquitetura e Schopenhauer. O problema da fruição e o lugar da arquitetura na teoria estética schopenhaueriana 
houvesse - isso também veio à tona na minha primeira inquietação - estendido ao polo subjetivo da fruição estética a sua compreensão (bastante pertinente, aliás) de que a arquitetura, diferentemente das demais artes, não nos fornece uma cópia, mas a coisa mesma. Ora, se assim for, a relação que o puro sujeito do conhecimento tem com ela não poderia ser a da mera contemplação visual, e sim, algo que o incluísse na própria obra, como seu ocupante. Qualquer tentativa de redução da fruição à mera contemplação converteria, de imediato, a arquitetura em mera cópia, ou imagem de si mesma - arte visual, apenas.

Parece advir daí, aliás, o relativo desconforto, ou mesmo a dificuldade de Schopenhauer ao tentar discernir um "campo arquetípico" próprio ao artefato ${ }^{29}$ - que hoje, talvez, chamássemos de objeto de design ou escultura de objetos. Schopenhauer, como se sabe - e ainda que contrariando seu mestre, o Divino Platão - vale-se quanto a isso de uma saída, de certo modo, sui generis: o artefato não possui uma Ideia própria, um arquétipo que lhe corresponda essencialmente, expressando apenas a Ideia relativa ao material de que é feito ${ }^{30}$. Ora, com um pouco a mais de atenção seria possível perceber que, sem essa artifício ad hoc, as mesmas determinações que regem a análise do belo arquitetônico - gravidade, reação à luz e simetria - poderiam muito bem ser aplicadas ao artefato. Em ambos está implícita a luta entre apoio e gravidade, bem como entre matéria e luz. E a ambos poder-se-ia aplicar a mesma lei fundamental: "nenhuma carga sem suporte, nenhum suporte sem carga"31.

Certamente é preciso levar em conta o esclarecimento feito por Schopenhauer nos Complementos, tomando a escala do objeto como determinante para sua apreciação estética: "o efeito estético [...] é diretamente proporcional ao tamanho do edifício", porque "somente as grandes massas podem fazer visível e penetrante em algum grau a ação da gravidade" ${ }^{32}$. No artefato, a expressividade decorrente da gravidade não se compararia proporcionalmente ao seu efeito na arquitetura, onde a relação entre o peso e os elementos de suporte seriam, digamos, bem mais avantajados. Ora, por mais que se concorde quanto à pertinência do argumento, há de se convir que se trata de uma distinção de grau, meramente; e

29 SCHOPENHAUER, A. WWV-I/MVR-I § 41, p. 284-5.

30 lbidem.

31 SCHOPENHAUER, A. WWV-II/MVR-II, cap. 35, p. 459.

32 Idem, p. 462-3.

A arquitetura e Schopenhauer. O problema da fruição e o lugar da arquitetura na teoria estética schopenhaueriana 
não, de espécie. Quando muito, concerniria à diferença por ele traçada entre o belo e o sublime - dessa vez, o matemático. Se assim for, seria preciso, então, reconhecer que Schopenhauer fruiria a arquitetura como quem contempla um artefato, e o artefato como quem contempla uma pedra. Com efeito, se a arquitetura distingue-se das outras artes plásticas, isto se deve a que, embora lide com a produção do artefato chamado edifício - e sob este aspecto poder-se-ia, com Schopenhauer, falar de uma arquitetura utilitária, submetida a "fins utilitários" ${ }^{33}$ - seu objetivo não seria propriamente este objeto, e sim, como vimos, o espaço por ele envolvido. Este, propriamente, seria o campo para a sua expressividade artística - e a arquitetura barroca, como vimos acima, seria um bom exemplo disto. Mas por outro lado - no caso, o lado subjetivo - a própria exigência simetria requerida pelo conhecimento artístico na metafísica schopenhaueriana indicaria que a relação que o puro sujeito do conhecimento tem com o objeto arquitetônico não pode ser a da mera contemplação visual. Isto implicaria, talvez, que não é a "imagem" do sujeito que deveria estar ali - ou o sujeito despido de si - mas ele próprio, em carne e osso, vivente. Fruir o espaço requereria uma relação outra com o objeto arquitetônico que extrapole os limites estreitos e não sinestésicos da mera contemplação visual - que certamente tem papel relevante, mas não definitivo -, ainda que esse alargamento nos leve a um grau ainda mais baixo de objetidade da Vontade, ou talvez, de volta à imersão no princípio de individuação. Este ponto nos leva ao problema da hierarquia proposta por Schopenhauer em sua metafísica do belo, do qual trataremos logo adiante.

Em todo caso, defendo que a fruição do objeto arquitetônico deve envolver algo mais que a mera contemplação visual e algo mais que a tridimensionalidade do objeto. Novamente, é Bruno Zevi quem sugere que: "toda obra de arquitetura, para ser compreendida e vivida, requer o tempo do nosso percurso, a quarta dimensão" ${ }^{34}$. Mas com a dimensão da temporalidade, ele mesmo reconhece, não nos distanciamos ainda de objetos tais como esculturas, que requerem o percurso como meio para a contemplação. O tempo, diz Zevi, seria apenas o instrumento "suficiente para definir o volume arquitetônico", apenas, mas não o espaço por ele gerado. Seria necessário, então, buscar algo que - na medida em que inclua o próprio 
sujeito da fruição - extrapole, inclusive, a dimensão temporal.

Aqui eu me aproximo da noção desenvolvida no breve, mas profícuo artigo de Edgar Graeff, um dos proeminentes arquitetos brasileiros da chamada geração modernista do século XX. Criticando Zevi, Graeff considera que não se trata de extrapolar ainda esta quarta dimensão, a temporalidade (afinal, que dimensão seria essa?), mas sim - num deslocamento perspectivo à moda schopenhaueriana - de situar o problema sob outro enfoque, pondo em cena, precisamente, aquele que chama de "sujeito da comunicação arquitetônica"35 - ou, para dizermos em linguagem de Schopenhauer: o sujeito da fruição do objeto arquitetônico. Sob este enfoque, o tempo já não seria mais apenas o instrumento de medição de um percurso, mas "o continente de fatos e processos diversos, como estar, viver certas situações, praticar determinados atos" ${ }^{36}$. Aquilo que eu chamaria de vivência e que, a despeito do apelo utilitarista, Graeff chama, talvez mais acertadamente, de ambiência. Citando o autor:

Caracteriza-se assim a forma arquitetônica como ambiência construída: ambiência revelada mediante a ação conjunta de um feixe de estímulos emitidos por formas plásticas - as formas da matéria sob a luz; formas táteis - temperatura, ventilação, umidade do ar; formas acústicas - sons, ruídos; e formas olfativas - odores, perfume. A conjugação dessas formas parciais na definição da forma arquitetônica é regulada pelo tempo de utilização do espaço construído ${ }^{37}$.

Com essa noção de vivência ou ambiência abre-se, então, o campo da fruição arquitetônica a uma relação sinestésica com o espaço que extrapola a mera contemplação. Isto implicaria, voltando a Schopenhauer, que seus correlatos: objetivo - o edifício como volume - e subjetivo - o sujeito como puro sujeito de conhecimento - alvos de minhas duas inquietações, talvez precisassem ser também repensados. Mas como?

\section{Hierarquia ou transversalidade?}

35 GRAEFF, Edgar. "A forma na arquitetura”. In: XAVIER, Alberto (org.). Arquitetura moderna brasileira: depoimento de uma geração, p. 213-4. 36 Idem, p. 214.

37 Idem, p. 216.

A arquitetura e Schopenhauer. O problema da fruição e o lugar da arquitetura na teoria estética schopenhaueriana 
Em uma visão de conjunto, arriscaria que as duas inquietações acima indicadas apontam para um problema de fundo, relativo à bem conhecida hierarquia das artes proposta por Schopenhauer em sua metafísica do belo. Com efeito, tomando-se a exigência de simetria que perpassa a relação entre sujeito e objeto em toda a obra, o Livro III de O mundo deveria nos apresentar uma leitura transversal: quanto maior o grau de objetidade, maior a importância do objeto artístico e menor a dependência do puro sujeito de conhecimento. Porém, falta-lhe precisamente uma psicologia desse puro sujeito de conhecimento, correlato ao objeto belo. Ficamos apenas com o objeto e, ao invés de transversal - ou inversamente proporcional sua leitura se mostra meramente ascendente, hierárquica. Ora, se a objetidade mais adequada da Vontade e a fruição do belo dependem, como se sabe, do objeto belo tanto quanto do puro sujeito de conhecimento, e se apenas a proporcionalidade entre ambos se altera na transferência gradativa de responsabilidade pela fruição da beleza - daí a noção de transversalidade a que aludi - poder-se-ia certamente falar de uma hierarquia do objeto artístico, mas não da própria fruição que, a rigor, exigiria alguma complementaridade entre ambos: objeto e puro sujeito de conhecimento.

Seguindo essa compreensão, a arquitetura talvez continuasse a se opor à música no que diz respeito à margem mínima de beleza concedida ao objeto arquitetônico, com o pouco que escapa ao utilitário - mas não, a meu ver, no que concerne à sua fruição, que envolve a abstração das circunstâncias e o deslocamento do objeto em relação ao curso do mundo. Certamente, e em oposição à música, sua fruição não implicaria a dissolução do puro sujeito de conhecimento, mas, talvez, o aprofundamento do indivíduo no princípio de individuação, tomando o espaço vivido como seu prolongamento: uma extensão ou expansão de si.

Curiosamente, aqui nos aproximamos das pesquisas recentes em neurociência, como as realizadas por Miguel Nicolelis - apresentadas em Muito além do nosso $\mathrm{eu}^{38}$ - que têm o cérebro como um grande simulador que, para além de nosso limite corpóreo, impele-nos a expandir nosso senso de eu no sentido da incorporação, não só das ferramentas que nos rodeiam, mas mesmo em direção a outros indivíduos, donde, por exemplo, noções como as de amizade e o amor. Ora, pela ótica schopenhaueriana, talvez seja essa mesma a plenitude da afirmação do 
princípio de individuação: construir, edificar, vontade de eternizar, ainda que à custa do sofrimento e da destruição inevitável. O espaço arquitetônico, sob essa compreensão, nada mais seria que o resultado de uma extensão ou expansão de nossa vontade individuada - a despeito da significação moral que se possa atribuir a essa extensão.

Chego ao final deste texto com a impressão de que as inquietações aqui expostas diriam respeito, como o próprio título sugere, muito mais à arquitetura que ao pensamento de Schopenhauer - ou, pelo menos, ao "resto" de arquitetura que ele deixa à margem de sua metafísica ${ }^{39}$. Em todo caso, e sob outro enfoque, talvez se tenha chegado aqui à mesma conclusão afirmativa de Nietzsche em um aforismo de Crepúsculo dos ídolos, ao tomar o arquiteto como um "grande ato de vontade, a vontade que move montanhas [...] [e] que exige tornar-se arte", bem como a arquitetura como uma "eloquência do poder em formas, ora persuadindo, até mesmo lisonjeando, ora simplesmente ordenando"40.

\section{Referências bibliográficas}

SCHOPENHAUER, Arthur. O mundo como vontade como representação (MVR). Trad. Jair Barboza. São Paulo: UNESP, 2005.

. El mundo como voluntad y representación II. Complementos (MVR-II). Trad. esp. Pilar L. de Santa María. 2a ${ }^{\mathrm{a}}$. Ed. Madrid: Trotta, 2005.

GRAEFF, Edgar. "A forma na arquitetura". In: XAVIER, Alberto (org.). Arquitetura moderna brasileira: depoimento de uma geração. São Paulo: ABEA/FVA/Pini, 1987. Pp. 211-7, p.212. Publicado originalmente em 1969, na Revista GAM (20).

NICOLELIS, Miguel. Muito além do nosso eu. São Paulo: Companhia das Letras, 2011.

NIETZSCHE, Friedrich W. Crepúsculo dos ídolos (Cl). Trad. Paulo César de Souza. São Paulo: Companhia das Letras, 2006.

ZEVI, Bruno. Saber ver a arquitetura. 5ed. Trad. Maria Isabel Gaspar; Gaëtan M.de Oliveira. São Paulo: Martins Fontes, 1996.

39 A guisa de excurso: Se pudéssemos ainda sugerir uma forma de reinserir esse "resto" e expandir as inquietações aqui apresentadas às artes em geral, penso que isto passaria por uma ressignificação da noção de fruição, enquanto deslocamento do objeto e do sujeito em relação ao curso do mundo. Tal ressignificação implicaria, no entanto, suprimir a limitação maior imposta pela noção de belo à expressividade artística - noção que, de todo, já não se mostra esteticamente significativa à arte contemporânea. Com isso, abrir-se-ia caminho para a compreensão de que qualquer objeto ou acontecimento poderia vir a ser deslocado em sua significação - ou em termos schopenhauerianos, fruído, tornado independente do princípio de razão, elevado à sua "ideia”. Entendida como deslocamento de sentido, desincumbida dos imperativos do belo, a noção de fruição ganharia uma abrangência capaz de envolver, por exemplo, obras como o urinol/fonte de Marcel Duchamp (1917) e a pop-art de Andy Wahrol (1968), representativas do fazer artístico contemporâneo. Até que ponto a própria metafísica do belo subsistiria a essa ressignificação é algo que demandaria pesquisas de maior porte. De todo modo, a meu ver, nessa reavaliação da noção de fruição residira a potência da estética schopenhaueriana em nossos dias. 40 NIETZSCHE, Friedrich W. A gaia ciência (GD/CI-IX) §11, p. 69. 
Aprovado: 18/12/15

Approved: 12/18/15 